\title{
Ueber die phytochemische Untersuchung der Fischfangpflanze
} (Verbascum sinuatum L.) und einiger anderer Scrophulariaceen berichtet. I. Rosenthaler. ${ }^{1}$ )

Unter dem Namen Fischfangpflanzen versteht der Verfasser solche Pflanzen, die ihrer Bestandtheile wegen beim Fischfange Verwendung finden; sie dienen, wenn sie ungiftig sind, als Lockmittel, wenn sie giftig sind, als Betäubungsmittel der Fische. Auf Anregung von Schaer hat Rosenthaler Verbascum sinuatum L. einer Untersuchung unterzogen, da, wie sich bei der Voruntersuchung herausstellte, die Früchte das wirksame Princip, ein Saponin, enthielten, so hat der Verfasser diese besonders berücksichtigt.

Zur quantitativen Bestimmung des Saponins in den VerbascumFrüchten verfährt man nach dem Verfasser in folgender Weise:

$10 \mathrm{~g}$ der gepulverten, lufttrocknen Früchte behandelt man im Extractionsapparate mit Aether, bis derselbe keinen Verdunstungsrückstand mehr hinterlässt. Die entfetteten Früchte erschöpft man dann durch Kochen mit Wasser und dampft die Filtrate unter Zusatz von Magnesiumoxyd zur Trockne ein. Den fein zerriebenen Rückstand kocht man viermal mit dem zwanzigfachen seines Gewichtes Alkohol von $95 \%$ aus, zieht den jetzt verbleibenden Rückstand mit heissem Wasser aus, filtrirt, dampft das Filtrat unter Zusatz von Magnesia zur Trockne and behandelt den nun bleibenden Rückstand noch zweimal wie oben mit Alkohol. Die vereinigten alkoholischen Auszüge dampft man ein, nimmt das Saponin mit absolutem Alkohol auf, verdunstet die Lösung wieder und trocknet das zurückbleibende Saponin bei $110^{\circ}$ bis zur Gewichtsconstanz. Die lufttrocknen Früchte ergaben im Durchschnitt $6,13 \%$ Saponin.

Das durch zweimalige Magnesiareinigung gewonnene Saponin ist rein weiss and verliert beim Erhitzen auf $120^{\circ}$ seine Farbe nicht; krystallisirt konnte es nicht erhalten werden. Von den meisten anderen Saponinarten unterscheidet es sich durch seine leichte Löslichkeit in kaltem, absolutem Alkohol und weiter dadurch, dass seine Lösung weder mit gesättigtem Barytwasser noch mit Bleiessig einen Niederschlag gibt. Es besitzt die für die Saponinkörper bezeichnenden Eigenschaften : seine Lösung schäumt stark und löst die rothen Blutkörperchen auf. Das Verbascum-Saponin besitzt in hervorragendem Grade die Eigenschaft, in Lösung pulverförmige Körper suspendirt zu erhalten. A uf das Krystalli-

2) Archiv d. Pharmacie 240, 57. 
sationsvermögen selbst gut krystallisirender Körper wirkt das Saponin in auffallender Weise ein, es verzögert das Auschiessen von Krystallen aus einer in der Hitze gesättigten Borsäure]ösung and lässt Salicylsäure aus heiss gesättigter Lösung nur mikrokyrstallinisch ausfallen. Es scheint optisch inactiv zu sein, schmeckt kratzend und wirkt Niesen erregend.

Auf dem Platinblech erhitzt, hinterlässt es eine sehr schwer verbrennliche KohJe, die beim weiteren Erhitzen allmählich unter Hinterlassung von wenig Asche verbrennt.

Das Verbascum-Saponin ist leicht löslich in Wasser, absolutem Alkohol, Weingeist jeder Stärke and Methylalkohol; schwer löslich in Amylalkohol und Aceton; unlöslich in Aether, Petroläther, Schwefelkohlenstoff, Benzol, Tetrachlorkollenstoff, Chloroform und Essigäther.

Die Lösungen des Verbascum-Saponins reagiren neutral. Streut man es in concentrirte Schwefelsäure, so umgeben sich die Theilchen des Saponins mit gelbrothen Höfen, die gelbrothe Strahlen in die Flüssigkeit aussenden, während sich die Flüssigkeit allmählich violett färbt; diese Färbung hält im unbedeckten Uhrglase etwa zwei Tage an und verschwindet unter Abscheidung schwärzlicher Substanzen. Durch Zusatz von Wasser wird die Violettfärbung aufgehoben.

Benutzt man bei dieser Reaction Schwefelsäure, die Kaliumpermanganat oder Chromsäure enthält, so umgibt sich das Saponin mit einem schwarzen Hof und die Flüssigkeit nimmt allmählich eine blaugrüne Färbung an.

Rauchende Salpetersäure färbt das Saponin kirschroth, beim Erwärmen wird die Flüssigkeit gelb.

In Salzsäure von 1,19 specifischem Gewicht löst sich das Saponin klar, beim Erwärmen trübt sich die Flüssigkeit.

Saponinlösung verändert ammoniakalische Silbernitratlösung in der Kälte nicht, beim Erhitzen tritt Reduction ein.

Mit Eisenchloridlösnng versetzt, bleibt Saponinlösung klar und trübt beim Erwärmen.

Mit Millon'schem Reagens gibt die Saponinlösung in dor Kälte eine Trübung, die beim Erwärmen verschwindet.

Beim Kochen des Saponins mit alkoholischer Kalilauge tritt eine sichtbare Veränderung nicht ein, auch dann nicht, wenn man die Flüssigkeit nach dem Erkalten ansänert. Versetzt man die Saponinlösung mit Brom so tritt nur Gelbfärbang ein. 
Das Saponin wird beim Erwärmen mit verdünnten Mineralsäuren leicht gespalten; Emulsin ist ohne Einwirkung. Saponinlösung reducirt Fehling'sche Lösung beim Erhitzen nicht.

Gegen Lösungen von Ferro- und Ferridcyankalium, Ferrosulfat; neutralem und basisch essigsaurem Blei, Baryumhydroxyd, Kalium- und Natriumhydroxyd, Ammoniak, Kobaltnitrat, Quecksilberchlorid und Kupfersulfat ist die Saponin]ösung indifferent.

Die aus der Elementaranalyse abgeleitete Formel ist $\mathrm{C}_{17} \mathrm{H}_{26} \mathrm{O}_{10}$. Nach einer mit der Acetyl-Verbindung vorgenommenen Molecular-Gewichtsbestimmung wird die Formel vielleicht richtiger durch $\mathrm{C}_{68} \mathrm{H}_{104} \mathrm{O}_{40}$ ausgedrückt.

Ueber Corydalisalkaloide berichtet J. Gadamer ${ }^{1}$ ) in einer sehr interessanten und ausfübrlichen Abhandlung.

Die Wurzelstöcke von Corydalis cava sind schon sehr bäufig der Gegenstand von Unterşuchungen gewesen, erwähnenswerthe Erfolge erhielten jedoch erst Dubbie and Lauder, Freund und Josephi und namentlch E. Schmidt und seine Schüler Noelle, Ziegenbein und Martindale ${ }^{2}$.

Die genannten Forscher haben durch ihre Arbeiten fünf Alkaloide isolirt, nämlich :

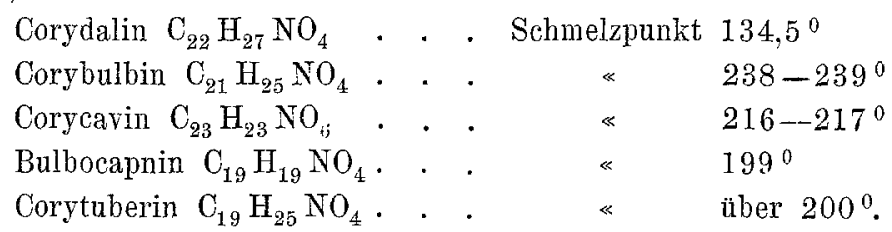

Ausserdem hat E. Merck noch auf ein sechstes amorphes Alkaloid, das Corydin, aufmerksam gemacht. Es soll von starker physiologischer Wirkung sein. Da der Schmelzpunkt dieses Körpers zwischen $65-75^{\circ}$ liegt, so dürfte dieses Corydin kaum als einheitliche Verbindung anzusehen sein.

J. Gadamer hat nun vor etwa 3 Jabren die Untersuchung über die Corydalisalkaloide wieder aufgenommen, um die vielfach zwischen den Angaben der einzelnen Autoren bestehenden Widersprüche aufzuklären und namentlich, um zu sehen, ob mit den bis jetzt isolirten Alkaloiden die Anzahl der Basen in Corydalis cava erschöpft ist. Die Methode,

1) Archir d. Pharmacie 240, 19.

2) Litteraturzusammenstellungen finden sich im Archiv d. Pharmacie 1896, S. 492 und 1898, S. 212; vergl. anch diese Zeitschrift 393, 505 und 36, 73. 